\title{
Author Correction: Functional organization and population dynamics in the mouse
} primary auditory cortex

Gideon Rothschild, Israel Nelken and Adi Mizrahi

Correction to: Nature Neuroscience https://doi.org/10.1038/nn.2484, published online 31 January 2010.

In the version of this article initially published, errors appeared in the last equation in the Methods section. It should have read:

$$
R_{\text {corrected }}\left(c_{i}, c_{j}\right)=\frac{\operatorname{COV}_{\text {corrected }}\left(c_{i}, c_{j}\right)}{\sqrt{\operatorname{COV}\left(c_{i}, c_{i}\right) \times \operatorname{COV}\left(c_{j}, c_{j}\right)}}
$$

Published online: 25 September 2020

https://doi.org/10.1038/s41593-020-00723-2

๑ The Author(s), under exclusive licence to Springer Nature America, Inc. 2020 